\title{
A theory of mobile library service delivery
}

\author{
Sarah-Jane Saravani and Gaby Haddow
}

\begin{abstract}
Research indicates there is widespread acceptance that nomadicity of library users is a phenomenon that will continue to increase; however, mobile learning is a resource that relatively few academic libraries appear to be taking advantage of. This paper presents a model developed during an investigation using a grounded theory approach into factors that may contribute to the delivery of library services to mobile technologies. A sample of 42 professionally-qualified library staff from the Australasian vocational education and training (VET) sector was investigated to determine how confident and capable library staff believed they were to respond to technology advancement challenges and the training and support required for that response. The resulting theoretical model explains the impact of mobile technologies on library services and highlights the complex factors contributing to mobile technology acceptance at both an organisational and individual level. The presence of a series of catalysing impacts forms a central core and their management can enable an organisation to move from a position of uncertainty to one where the consequences of mobile technologies have been normalised.
\end{abstract}

\section{Keywords}

Mobile technology, mobile library services, library competencies, capability development, technology acceptance, Vocational Education and Training libraries

\section{Introduction}

Systems implementation is a major organisational investment and a crucial indicator of successful implementation is employees utilising the new technologies competently. Persuading users to accept and integrate new information technologies (IT) persists as an on-going challenge implicit in the implementation of new information systems. Institutions of higher learning have recognised the importance of technology to educational delivery and have invested heavily in developing information and communication technologies in education (Evans, 2005; Facer, Faux and McFarlane, 2005; Kim, Mims and Holmes, 2006). The ability to learn anywhere, anytime is increasingly being regarded as a business-as-usual approach across the higher education and VET sector. In other words, the process of learning need not separate the learner from their normal activities or routines; learning can be delivered in a manner that either enhances such activities or allows them to occur in tandem with that process. The convenience that this type of learning offers adds to its appeal and the trend globally is towards the delivery of education through mobile devices that free up the time, the place and the 
means of the learning exchange (Sharples, Taylor and Vavoula, 2005: pp. 2, 4; Traxler, 2008; Valk, Rashid and Elder, 2010).

As demand for online access to information increases, libraries have been actively embracing initiatives to digitise and preserve physical materials, to store them in online repository systems and to encourage their free access via the Web (Aldrich, 2010; Emanuel, 2010). A growing body of literature in the field indicates the academic library sector has engaged in early and sustained ventures into assessing the changing nature of the library and current or future impact of environmental pressure points, such as space utilisation, technology infrastructure and learning provision, the future shape of learning provision and seeking to capture their potential value (Australian Library and Information Association (ALIA) TAFE Library Advisory Committee, 2009; Canuel and Crichton, 2010; Hallam, 2008, 2009; Latham and Poe, 2012; Newton, Miller and Bracke, 2011). Studies describe models of service delivery and physical spaces that are continually evolving in response to the presence of technology (Lippincott, 2008a; Pang and Johanson, 2008; Weir, 2000). The introduction of computing technologies, provision of online delivery and planning for altered physical spaces appears well embedded, although not all researchers agree with this view. Some opinion-shapers, while urging the key benefit of mobile learning as being its potential for increasing productivity through learning becoming available anywhere, anytime, warn it is a resource that relatively few academic libraries are taking advantage of (Cao, Tin, McGreal, Ally and Coffey, 2006: p. 1289; Lever and Katz, 2007). This view is echoed by Arms, Calimlim and Walle (2009: para. 7) who make the claim that, in a world in which rapid technological change is the norm "All libraries are inflexible and digital libraries are no exception. They require big investments of time and money and react slowly to changing circumstances". The challenge to enable digital access to users on the move, combined with the presence of students with handheld devices integral to their personal lives and learning environments, has focused many academic library administrators on the implications of this phenomenon.

Generally, there appears to be widespread acceptance that nomadicity of library users is a phenomenon that will continue to increase (Aldrich, 2010; Hitch and McCord, 2004; Lippincott, 2008b) and that such mobility will affect both user expectations and library services. One of the crucial issues raised by this acceptance is that of impact and response: how prepared are libraries to respond to the challenges/opportunities that the latest wave of technology advancements is presenting? Persuading employees to accept new systems is fundamental to successful implementation (Jasperson, Carter and Zmud, 2005; Venkatesh, Brown, Maruping and Bala, 2008; Yi, Jackson, Park and Probst, 2006); the question, therefore, arises as to the readiness of library staff and their levels of confidence and capability in responding to those challenges. To date, the impetus of investigation into libraries and mobile technologies has focused on services and products, 
interfaces and systems usability (Kroski, 2013; Mtshali and Iyamu, 2013; Saxena and Yadav, 2013), there is little empirical evidence of the impact mobile delivery has had on libraries and, in particular, on staff members, from the viewpoint of planning, processes and professional development. While studies are beginning to engage with these factors (Sharma and Sahoo, 2014), the preparedness or capability of staff to leverage mobile technology potential remains an emerging and critical issue to ensure library and information professionals are appropriately prepared to engage effectively with mobile technologies in the workplace. This is an imperative that has implications for staff development, service improvement and student benefit. It is the contention underlying the investigation discussed in this paper that staff confidence and competency with mobile technology is vital; it exerts a crucial impact upon organisational outcomes and frequently exists within a wider context of costly infrastructural support. To date, research into the deployment of mobile technologies in the learning environment have not fully explored the potential for hesitant uptake of mobile devices for learning or information access as a result of staff lacking capability or competence with mobile technology. The present research addresses these issues by examining mobile technology acceptance and service delivery by VET library staff. It was anticipated the information generated from the investigation would inform a greater understanding by library decision-makers of issues affecting the sector in relation to technology impact.

The investigation explored the competencies required of VET sector library staff in Australia and New Zealand to deliver services to mobile technologies. It focused on the current state of preparedness of VET libraries to deliver mobile services within a framework of innovation and technology adoption. Two overarching questions framed the study: how do library staff respond to the concept of the mobile technology library (m-library) and what are their perceived levels of confidence and capability within this environment; and what is the best way to address any identified competency gaps in a systematic and replicable manner? The model presented in this paper is based solely on the investigator's research and data. It is a model that is open to further use, testing, discussion and application to other situations. Subsequent research can test the model for robustness and longevity and may offer modification.

\section{Context of Study}

The study arose from an interest in the extent to which academic libraries had progressed towards implementation of service delivery to the mobile devices students were carrying. There was a paucity of empirical information relating to the VET library sector and the impact of mobile technologies upon this sector appeared restricted predominantly to anecdotal reporting. An assumption was made that a contributing factor to the apparent slowness in the uptake of mobile service delivery across the sector was a lack of confidence and competence amongst the library staff themselves. 
The study was grounded in the acknowledgement that both technologies and expectations of their capabilities are changing rapidly, with the current usage trend being towards technologies that allow individual mobility and, increasingly, contextualisation (Younas and Mostéfaoui, 2011). Placing this phenomenon within the VET library environment, the study sought to identify factors that were influencing the ability of libraries to engage with the potential of mobile technologies, framed by two research questions:

What skills, knowledge and competencies are required by library staff to develop and deliver mobile technology services in the vocational education sector?

What specific on-the-job training is required by library staff in the vocational education sector to acquire the skills, knowledge and competencies to effectively develop and deliver mobile technology services?

\section{Methodology}

An inductive approach was carried out for data collection and analysis in this study. Overall, the theoretical paradigm essential for the design and implementation of the research followed a purely qualitative approach.

In order to gain rich information on the subject under investigation, semi-structured interviews were conducted with forty-two staff from six Technical and Further Education (TAFE) libraries in Australia and eight Institutes of Technology and Polytechnics (ITP) libraries in New Zealand. As well as the interview questions that probed the research questions, this purposive sample was asked a number of demographic and profession-related questions. The purpose of these questions was to gather information about individual staff levels of technology competence and their length of service in the profession. This information, and the position (service experience) participants held within their library, which included the three positions of library manager, systems librarian and qualified librarian, was used for comparative purposes and to identify relationships and trends when analysing the data. The demographic and profession-related data allowed for close interrogation of results and proved to be fundamental factors in the ability to predict staff response to technological change impact. The variable 'career factors' (position and service length) were influential in all aspects of the investigation and formed a component of the resulting theoretical model. Several investigations into innovations and library professional development have developed demographic profiles using a range of similar variant items (Maesaroh and Genoni, 2009; Rabina and Walczyk, 2007). The interview transcripts and responses to the demographic and profession-related questions were the primary sources of data analysed. 
The intention to investigate a particular phenomenon, identifying and addressing technology competence in the library workplace, and to allow the social interactions, relationships, interpretations and meanings to emerge, a constructivist, interpretivist approach was taken to the research. The constructivist perspective focuses on a subject's interactions with the world and their construction of meanings from that interaction (Gray, 2004: p. 17). The interpretivist approach attempts to provide meaning and, as an inductive method, "seeks to find internal logic of the subject" (Gray, 2004: p. 21). The individual is the unit of analysis; his/her experiences within their "world" and the meanings of these experiences form the focus for the researcher. Grounded theory was considered by the researcher as the most appropriate research methodology for the investigation. The process of grounded theory methodology includes the formation of response categories, or "abstractions of phenomena observed in the data" (Chenitz and Swanson, 1986: p. 94). These categories, through constant comparison, gradually develop into a theory intended to interpret the meaning of the collected data. Immersion in the raw data, in this case interview transcripts, and comparing, considering, categorising and seeking illumination on a progressive basis through to the development of abstract theories that provide insight into human behaviour, enabled exploration of the lived experience of the VET library staff and their interpretations of it. From the data collected, an understanding of staff experience was gained, leading to the construction of a set of theories and a resultant model.

\section{The analytical process}

The analytical process sought to understand: the introduction of technologies into the library environment and its impact upon required knowledge and competencies amongst VET library staff; the perceived requirement for capability development training; and the preferred methods for delivering such training. Data analysis included a description of incidents, discussions, examples, relationships, exclusions, unanticipated classes of data, and alternative explanations, and also included analysis of how these aspects of the participants' experience interacted. This first stage of the analysis resulted in a range of response categories being formed that were then subjected to further analysis during which related patterns were revealed and reconfigured in increasingly-abstract conceptual themes.

\section{Conceptual themes}

The development of conceptual themes comprised the second analytical level - the intermediate, or focused, coding phase. These were formed by looking for patterns and relationships within the many different categories identified at the first stage of analysis. They led, in turn, to the development of abstract concepts. The conceptual themes do not appear in the final model, except in summarised form below the three overarching theoretical elements. During this analytical phase a range of 'impacts' 
were identified. These nine impacts were found to be important to one or more of the conceptual themes and allowed the emergence of relationships within and between one another, facilitating analysis at the third, advanced theoretical coding stage.

\section{Abstract concepts}

The development of abstract concepts resulted from analysing the conceptual themes that had emerged in relation to an aspect of the investigation. For example, the conceptual themes that were derived from interview data relating to general technology adoption and impact were interpreted as the abstract concepts of context, consequences (immediate) and consequences (observed). As illustrated in the 'Environment' section below, each of these abstract concepts had been subjected to a unique impact. The abstract concepts serve to focus the main elements contained within the conceptual themes and demonstrate at a higher level of analysis the insights that enabled the researcher to consider the integrated theory. Their contribution to an understanding of the phenomenon under investigation lies in their ability to define both the problem and the response at an abstract, intermediate level.

\section{Impacts}

A range of components identified as impacts was identified during the development of conceptual themes. The impacts were found to be important to the conceptual themes and to the higher level abstract concepts. Some impacts were associated with technology, a logical finding given the focus of the study, and others with staff attributes and environmental factors. The presence of an initial impact created by students with mobile devices interacting with library services was in fact fundamental to the problem that led to the investigation. The impacts were identified as influencing the conceptual themes, each containing potential for disruption and uncertainty within the theme under consideration. They might be regarded in the light of catalysts that appear to be sequential, in that each impact has elements of the previous abstract concept contained within it. Taking the example of 'Content', which includes the library services most effectively delivered within the mobile environment, the associated impact 'mobile technologies' contains elements of the previous conceptual themes of staff skills, technology and workplace change and the technology interactions of students with the library. These elements are contained within the disruptive influence of the catalysing impact.

Nine impacts, constituting a range of features from the new technologies that prompted the investigation through to change impact that affected staff response to changes, were identified as influencing the abstract concepts. The presence of these nine impacts generated a condition of uncertainty upon specific aspects of the investigation. For example, the impact of new technologies affected the context within which the investigation took place. It exerted the influence of uncertainty over the themes of augmented delivery of service, information and workplace infrastructure. In other 
words, this impact caused VET library participants to view changes to the environment in which they worked through the specific focus or impact of new technologies. As the analysis continued, it became evident that management of these impacts was central to explaining the individual and organisational responses that were occurring.

\section{Development of a continuum}

Continual comparison of themes and the emergence of theoretical elements eventually reached the point, termed by Glaser and Strauss (1999), of "theoretical saturation", whereby further analysis adds no new understandings. The insights obtained by the researcher during the final high-level analysis of abstract concepts consolidated the data into an integrated theory. This theory encompasses the diversity and similarities within the collected data, and offers an interpretation of the impact of mobile technologies on library staff - including context/environment, required skills, professional development and resulting changes in working relationships - at a theoretical level. From the continual analysis of data and based upon the sequence of interview questions which formed a continuum of enquiry, a continuum of conceptual themes and impacts was developed. This continuum is discussed in the following section; the integrated theory that emerged from high level analysis of the continuum is subsequently presented.

\section{Results}

During the first level of analysis, response categories were identified and formed the basis for the impacts and conceptual themes. At a higher level of analysis, the conceptual themes led to abstract concepts, each subjected to a unique impact and these then formed a framework comprising three overarching theoretical elements: environment, new knowledge generation, and capability development. Critical to part of the first and all of the second and third elements are the impacts that may hinder or enable the effective adoption of mobile technologies in library services. Contained within each of the theoretical elements are the summarised conceptual themes in the sequential order discussed in the abstract concepts continuum.

Of the three demographic variables selected for the investigation - position, service experience and technology competence - the analysis found position as having the most influence on responses, with service length exhibiting lesser influence. Technology competence did not appear to have any clearcut influence and this variable has, therefore, been omitted from the discussion below and the resulting theory. For the purposes of brevity and focus, only important differences relating to position are reported in the sections that follow. 


\section{Environment}

The theoretical element 'Environment' relates to the background context within which the impact of mobile technologies upon library staff is occurring. It includes the immediate consequences of this context, in other words, the manner in which library staff believe they had responded both operationally and attitudinally, and also the observed consequences, or the manner in which students had responded to the context and the subsequent effect upon library staff.

In assessing the question of new technology adoption by the library, a contextual situation (abstract concept) was created in response to the new technologies (impact) entering the library environment. This contextual situation arose from response categories that formed three distinct components (conceptual themes): information delivery; infrastructure; and service delivery. The definitions associated with the various conceptual themes that follow are specific to the present investigation.

\section{Impact - new technologies \\ Context}

1. Information delivery - defined as the dissemination of information to information users through the implementation and use of software and programmes by information providers

2. Infrastructure - defined as processes, procedures and technologies that enable delivery of services and information

3. Service delivery - defined as enabling the provision of service to clients

When considering the impact the adoption of new technologies was having upon the library workforce, the impact of staff response and involvement in technology affected how participants viewed adoption impact. Analysis of the data generated an immediate consequences abstract concept which comprises conceptual themes of staff attitude and immediate and wider workplace support.

\section{Impact - personnel}

\section{Consequences (immediate)}

1. Processes and relationships - defined as interpersonal work-related relationships which exist and develop within an organisation, and a range of interrelated work tasks intended to achieve a specified result

2. Attitude - defined as a disposition towards an event, an object or a person

3. Organisational support - defined as employees' perception of their organisation's response to, and acknowledgment of, their individual and group contribution and value

4. Job design - aspects of a job, such as content, methods, and relationships, required to fulfil technological and organisational requirements as well as recognising the contribution of the job holder 
Staff perceptions and beliefs formed a critical impact defined as 'attitudes' in relation to the question of how new technology had affected them. The responses reflected what they perceived as occurring around them and these combined to form the abstract concept 'consequences (observed)'. The observed consequences comprise a focus on skills, technology and workplace change, and a perception of altered student expectations and interactions.

\section{Impact-attitudes}

\section{Consequences (observed)}

1. Skills focus - defined as competence within one's particular area of workplace practice

2. Technology focus - defined as the use of computing hardware/devices and software to manage the information environment

3. Workplace change focus - defined as instilling new values, attitudes and behaviours within a working environment in order to achieve new ways of doing work and to overcome resistance to change

The impact of new technology was also seen as affecting student behaviour in the environment. The interview responses associated with the question of the impact upon student library experience resulted in three conceptual themes, within the 'consequences (observed)' abstract concept:

1. Service expectations - defined as receiving the quality of service required to satisfy particular needs

2. Interactions - defined as student interactivity with library facilities and services, both physically and digitally

3. Technology usage - defined as student engagement with computing hardware/devices and software within the information environment

The abstract concepts that emerged focus on workplace change and support, both organisational and infrastructural, and staff response as individuals and within the context of environmental change.

\section{New knowledge generation}

Having established an environmental context to the impact of new technologies, the analysis then identified a requirement for the generation of new knowledge. VET library staff were asked what library services could, most appropriately, be delivered within the mobile environment and what knowledge and skills were required to work effectively in this environment. Participants were also asked to consider what methods would be most useful to identify any gaps existing between their current knowledge and skills and the required levels. 
The required new knowledge component of the investigation was similarly impacted by mobile technologies and the need to respond appropriately. In seeking information about what library services would be most effectively and appropriately delivered within a mobile environment, the abstract concept of 'content' emerged. 'Content' was drawn from the conceptual themes 'study- and information-related services' and potential 'technical issues'.

\section{Impact-mobile technologies}

\section{Content}

1. Study-related - defined as services conveying information supporting the conduct of study

2. Informational - defined as guidance on the operations, functions and purpose of the library

3. Technical issues - defined as service matters relating to hardware, software or telecommunications features

Over half the VET library staff participants indicated their belief that the most effectively-delivered library services within a mobile environment were study-related. Their responses related technologyenhanced services with student academic success.

When asked what skills, knowledge and competencies were required for effective work within the mobile environment, participants identified types of capabilities that fell into three distinct conceptual themes: ability to adapt; technical competencies; and management issues.

\section{$\downarrow \quad$ Impact-new knowledge \\ Capabilities}

1. Adaptability - defined as the ability to engage with work-related opportunity

2. Technical - defined as information technology, software or hardware skills

3. Management - defined as facilitating the attainment of organisational goals

In the first stage of analysis, nearly half the response categories identified contributed to the adaptability conceptual theme. The technology theme was established from approximately a third of the categories and the management theme comprised the remaining categories. The most frequentlymentioned competencies were all related to adaptability. Technical competencies were also regarded as important and covered a range, from the specific, such as knowledge of coding languages, through to the general, such as a grasp of computing basics. The management theme, covering such aspects of knowledge as an understanding of the main trends and capabilities of mobile technologies, and developing a collaborative relationship with the information technology departments around skills development, highlighted a concern for where the library should be positioned. 
The themes consolidate the response categories that indicate the linkage between knowledge and competencies required and student expectations of library services, in areas such as knowledge to answer student queries, competencies to deliver value-added services, and a capacity to identify and address worthwhile challenges in the mobile environment.

Having established 'capabilities' required for effective mobile library service delivery, participants were asked to consider what methods or techniques would be useful to identify the gap between the required capabilities and current knowledge and skills. Three distinct conceptual themes emerged: internal reviews, routine organisational processes and external opportunities. Together these themes are described by the abstract concept 'correlation', reflecting the need to match existing and required capabilities.

\section{$\downarrow$ Impact-techniques}

\section{Correlation}

1. Internal review - defined as a formal assessment conducted within the boundaries of a specific work unit

2. Organisational processes - defined as the structured activities through which the organisation arranges its work

3. External opportunities - defined as events related to professional development that occur outside the organisation or, in some cases, outside the operational unit

Response categories indicated a preference for simple, direct methods of determining skills gaps. Almost half the sample believed a survey would be the best way to obtain the information. The second most preferred method was to ask other staff. This approach was also associated with holding general conversations with staff to identify gaps in competence and by library managers initiating individual discussions with staff.

As described above, an understanding of the new knowledge requirements for the environment in which library staff were working was drawn from the data. The third overarching theoretical element, 'capability development', emerged as a response to the previous element.

\section{Capability development}

The third theoretical element focuses on the capability development of staff and includes aspects relating to on-the-job training requirements, best delivery mechanisms and the overall impact of mobile service delivery upon staff roles and relationships. 
This theoretical element comprises the abstract concepts of 'capability', 'conduct (the process of being conducted)' and 'consequences'. The abstract concept of 'capability' is strongly influenced by the impact of training, reflecting the participants' suggestions for on-the-job training necessary to acquire the skills, knowledge and competencies to effectively develop and deliver mobile technology services. Three conceptual themes were identified in the data and these ranged from specific to general: to address technical needs; to enhance service delivery; and to develop specific or general competence.

$$
\text { Impact - training }
$$

\section{Capability}

1. Technical - defined as information technology, software or hardware skills

2. Service delivery - defined as enabling the provision of services to customers

3. Competence - defined as demonstrated workplace-related ability and understanding

Response categories indicated an interest in training that directly related to the context within which libraries were operating, for example, training on identifying requirements for developing mobile services, on matching essential technologies with users, on the use of mobile technologies within education, and on a general understanding of the mobile environment. Other types of training that emerged included specific technical training, such as understanding of file sizes suited to small devices so that useful information literacy tutorials could be created; on how to develop and include gaming within information literacy tutorials; and how to create LibGuides for small devices, training on browser displays, file size requirements, coding and programming languages, text editing tools and digital data management. An interest in training on comparison of device functionalities was also noted,

Response categories displayed a preference for hands-on, self-paced learning with the time commitment being factored in. Working with a range of mobile devices emerged as a considered priority for successful acquisition of competencies. Time spent learning theoretical concepts was not reported as a preferred method but rather experiential, action-based, applied learning.

The training component comprised several features: staff interest and ability to learn new technologies themselves; that the learning should occur in-house without the need for external intervention; and time to experiment with the devices.

Moving from training requirements to delivery methods for that training, participants were asked to consider their preferred types of training. The abstract concept, 'conduct', which comprises two distinct conceptual themes, emerged from the data. The themes are: informal delivery and formalised 
delivery of training. The stated preference for experimentation with technology in order to acquire necessary mobile technology skills forms the impact upon how training should best be delivered.

$$
\text { Impact-delivery methods }
$$

\section{Conduct (the process of being conducted)}

1. Informal availability - defined as gaining experience on the job through exploration

2. Formalised delivery - defined as meeting learning objectives through structured processes

VET library staff indicated a preference for informal types of training methods, with more than half the coded response categories contributing to this conceptual theme. It involved hands-on experimenting and learning with mobile devices, ideally with an expert mentor to assist at point of need.

The final component of the continuum relates to staff being asked to consider how roles, relationships and working practices had adapted or were expected to evolve as a consequence of mobile delivery. The impact of change affected the three overarching conceptual themes differently. These three themes were: altered roles, collaborative relationships and adopter types.

\section{Impact - change impact}

\section{Consequences (immediate, impending)}

Roles:

1. Refocus - defined as changing the emphasis or direction

2. Continuation - defined as remaining with particular requirements and conditions

3. Adjustment - defined as a small alteration made to align with a new situation

Relationships:

1. Collaboration - defined as active, interdependent engagement to provide a value-added solution

Working Practices:

1. Change accommodation (early adopters) - defined as acceptance or incorporation of change to enable a desired outcome

2. Cautious approach (late adopters) - defined as moving hesitantly to be alert for potential problems

In the initial analysis of role adaptation, almost three-quarters of the response categories related to the 'refocus' roles conceptual theme. The 'continuation' roles theme and the 'adjustment' theme 
comprised less than a fifth and a tenth of the categories, respectively. The finding that most of the VET library staff believed that their roles had changed and would continue to evolve links closely to the next conceptual theme, 'relationships', where all categories drawn from the data focused on collaborative opportunities resulting from the mobile technology environment. This was seen in the responses from staff at all libraries sampled that they were beginning to work closely with colleagues from outside the library. Finally, over half the categories identified in relation to the conceptual theme 'working practices' were associated with participants accommodating change in their workplace, while a minority were taking a wait-and-see approach.

\section{Abstract Concepts Continuum}

The overarching theoretical elements that have been presented in the sections above are combined below in condensed form to demonstrate the continuum of analysis and comparison that led to the development of an integrated theory. As noted above, the continuum reflects the sequence of interview questions which formed a structured focus of enquiry to identify the primary factors involved in mobile technology acceptance in libraries. The abstract concepts continuum pulls together the various findings into a sequential, cohesive explanation that enabled the researcher to consider the theoretical model.

\section{Environment}

\section{$\downarrow$ Impact-new technologies}

\section{Context}

Augmented delivery of service, information

Workplace infrastructure

$$
\text { Impact-personnel }
$$

\section{Consequences (immediate)}

Staff attitude

Immediate and wider workplace support

$$
\underset{\text { Consequences (observed) }}{\downarrow}
$$

Focus on skills, technology and workplace change

Altered student expectations and interactions

\section{$\underline{\text { New knowledge generation }}$}




\section{Content}

Study- and information-related services

Potential technical issues

Impact-new knowledge

\section{Capabilities}

Technical competencies

Management issues

Ability to adapt

$\downarrow$ Impact-techniques

\section{Correlation}

Internal reviews

Routine organisational processes

External opportunities

\section{Capability development}

$$
\text { Impact-training }
$$

\section{Capability}

Address technical needs

Enhance service delivery

Develop specific or general competence

$$
\text { Impact-delivery methods }
$$

\section{Conduct (the process of being conducted)}

Formalised delivery

Informal availability

$$
\downarrow \text { Impact-change impact }
$$

\section{Consequences (immediate, impending)}

Refocused roles

Collaborative relationships

Range of adopter types 


\section{Integrated Theory}

The model that is presented is based solely on the investigator's research and data. Where previous, comparative research exists this has been referred in the development of the model.

As discussed earlier, the emergence and relationship of response categories to one another contributed to the gradual development of theoretical links between the categories and the development of higher level abstractions. A continuum of theoretical elements and accompanying impacts was developed and served to address all major facets of the phenomenon under investigation. As the resulting theoretical model illustrates, the overarching theoretical elements contributed to important components of the model; organisational, individual and contextual. The integrated theory encapsulates the commonalities and diversity of data captured in the investigation and has been presented in diagrammatic form to demonstrate progression through the conceptual sequence of the phenomenon. The background need or problem of a changing environment led to awareness of the need for new knowledge to cope with these changes. The process of acquiring such knowledge occurs through the availability of capability development opportunities. The outcome, or goal, of such activity is a new model of delivery and an environment of dynamic equilibrium, a situation described by Rogers (2003: p. 471) as denoting the rate of change in a social system being commensurate with the system's ability to cope with it. A process of normalisation is associated with the successful attainment of dynamic equilibrium. The model progresses from broad organisational level to individual unit level and, finally, back to organisational level, somewhat resembling an hourglass structure. Rogers (2003) presents a comparable model with his five-stage innovation process in organisations, with stages 3 and 4 in the implementation phase offering potential for individual members of the organisation to receive primary focus.

During the development of the theory a central core emerged which draws the other themes into a cohesive, meaningful relationship. The central core provides the pivot around which other components revolve and was termed 'Impact consolidation'. The presence of impacts was observed throughout the investigation and, as noted, the impact students with mobile devices had on library services was fundamental to the problem under investigation. The nine impacts identified and integrated into the theoretical continuum proved to be central to the investigation, in that by managing their effects the major components of the theoretical model could be brought into meaningful relationships. The initial impact of new technologies was an external factor and could not be managed, however, the other two impacts within the environment thematic element - personnel and attitudes - were internal and could be managed. The final impact - impact change - which exerts a disruptive influence upon the workplace components of roles, relationships and working practices 
prepares the way for outcomes such as the institutionalisation, or normalisation, where the innovation becomes a routine part of the organisation.

In the model, consolidation of the impacts indicates acknowledgement of their influence. A fundamental requirement of addressing the influence of impact conditions, processes or consequences is the ability to minimise the uncertainty these impacts have the potential to create. This was evident in the two theoretical elements of generating new knowledge and developing capability. If, in the process of defining, acknowledging and managing the effect of impacts, the generated uncertainty can be minimised, then the resulting, desired condition of maximised benefit may be realised. For the present investigation, maximised benefit was described by VET library staff participants as including a stage of capability development which would assist the attainment of anticipated consequences, such as effective mobile service delivery, and dynamic equilibrium, the stage where attainments become normalised.

The central core, impact consolidation, shown in Figure 1, consists of two conditions: impact requirement and impact management, and two associated strategies: minimise uncertainty and maximise benefit. Impact consolidation means that all associated impacts are identified and brought together in such a way that their influence, if not necessarily able to be controlled, can at least be recognised and responded to. Within the core focus of impact consolidation two major activities are occurring. Impact requirement has as its impetus the activity of minimising the uncertainty the impacts have been identified as creating. The second condition, impact management, has as its central impetus the activity of maximising the benefits to be gained from the impacts. The theoretical element 'capability development' is a substantial response to this. The condition of maximising benefits, as viewed through the lens of the present research, means to address identified requirements, or rectify observed disruption, in the most effective, sustainable manner.

For the specific purposes of the present investigation a selection of career-related variables was included through which to collect and analyse the data. Although they have some influence in all stages of the investigation as illustrated in the results presented above, their role is most evident during the second and third theoretical elements - new knowledge generation and capability development - where factors influencing personal acceptance and use of mobile technologies are focused upon. The first theoretical element environment, and the final desired goal, anticipated consequences and dynamic equilibrium, describe service unit (library)/organisational level factors and are less directly influenced by the selected variables. The model includes within the theoretical elements a selection of the conceptual themes, intended, as a prompt, to illustrate aspects of the element. For this reason the intermediate abstract concepts have not been included. 


\section{Integrated theory}

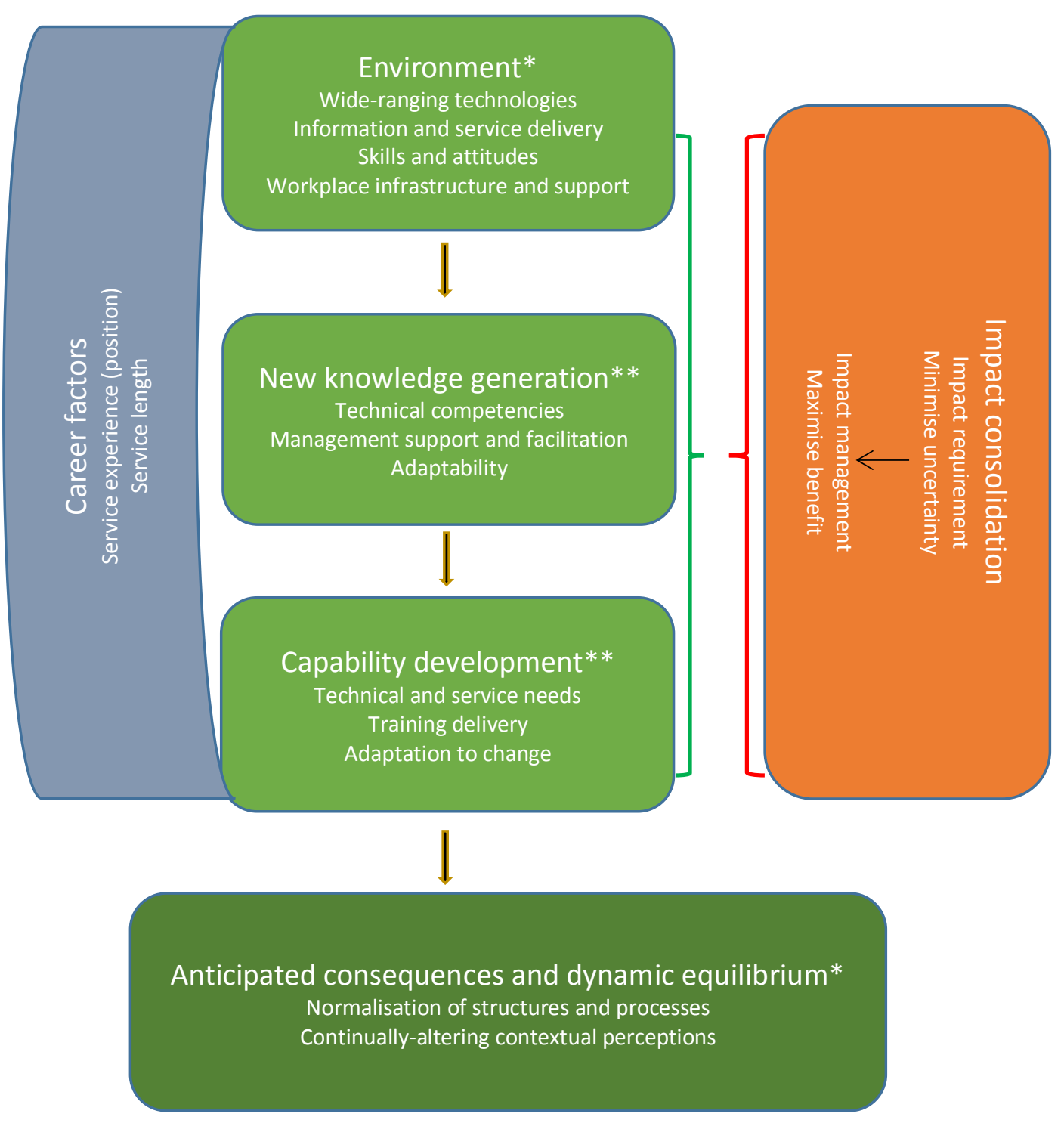

(* Organisational level, ** Individual level)

Figure 1. Theoretical model explaining impact of mobile technologies on library services.

\section{Discussion}

Grounded theory provides a framework for systematic qualitative data analysis with explicit analytic procedures and research strategies (Charmaz, 2000: p. 512), with a focus on theory generation to illuminate human behaviour and the social world (Chenitz and Swanson, 1986: p. 7). The benefit of grounded theory is the ability for themes to emerge from the stories told to the researcher and the drawing of these themes into coherent and meaningful form. The richness of the data is preserved through the structuring process. The emerged theory, based on data rather than assumptions, has 
longevity, "[as it] is too intimately linked to data, it is destined to last despite its inevitable modification and reformulation" (Glaser and Strauss, 1999: p. 4).

In applying the grounded theory approach to the questions this investigation sought to answer it became clear that the answers were complex. The integrated theory that resulted indicates that skills, knowledge and competencies, and the training required to develop these, cannot be isolated and offered out of the contextual environment. There exists an impetus behind the desire to acquire knowledge and there is a consequence of the acquisition and application of that new knowledge. The responses of VET library staff who participated in the investigation showed a strong awareness of changing environmental conditions; they perceived an alteration in the context within which they were working. While some participants believed their organisations were not paying sufficient regard to environmental changes, all provided evidence of how, as individuals, they were responding. They were articulate in their perception of anticipated consequences of mobile devices upon the work unit/organisation and how far they had moved towards the attainment of dynamic equilibrium, or the normalisation of their attainments.

The influence of a variety of impacts upon specific areas of the investigation are explained and illustrated in the integrated theory model. The theory is used as a basis for comparing essential thematic layers and interrelationships and highlights the complexities that influence technology acceptance and usage. The central core of impact consolidation enables the generation of new knowledge to result in a beneficial outcome through the acquisition of appropriate skills. This, in turn, prepares the way for a refocus from the individual to the organisational level, wherein the consequences of workplace change can assume an institutionalised, routine aspect, identified in the model as dynamic equilibrium. The theory commences at organisational level, narrows to individual unit of analysis, and then expands to organisational level at the final process outcome.

In addressing the research questions: what skills, knowledge and competencies are required by library staff to develop and deliver mobile technology services in the vocational education sector; and what specific on-the-job training is required by library staff in the vocational education sector to acquire the skills, knowledge and competencies to effectively develop and deliver mobile technology services, the investigation identified three major elements that contribute to understanding the phenomena. These are, firstly, environment or contextual perceptions (including various environmental aspects operating at the work unit or organisational level), and, secondly, new knowledge generation (including the beliefs and interpretations of staff regarding the type of content knowledge they required to be successful and the range of capabilities they needed to master and the manner in which they could best attain these). The third major element, development of capability (including identification and establishment of outcomes, and the consequences of such activity), leads towards the desired 
organisational goal of the implementation and normalisation of emergent thinking structures and processes. This final state, using the term coined by Rogers (2003) as dynamic equilibrium, is subject to continually-altering contextual perceptions. The theory can be regarded as being inherently cyclical.

During the course of the study several limitations in approach that had the potential to influence the findings became evident. The investigation showed a profession very aware of the impact of mobile technologies upon the workplace and recognition of the need to respond to the impact of mobile technologies through up-skilling and having access to technology. However, length of service and technology competency did not provide the level of variation that previous research has suggested. It is possible that sample gathering contributed to this outcome. The sample selection was purposive and targeted experts in the field of library and information studies in two neighbouring countries, distinguished by strong similarities in professional culture. Such a sample can be assessed on its own characteristics but that assessment may not be applicable across a wider population (Babbie, 2010; Cohen Manion and Morrison, 2010; Denscombe, 2010; Silverman, 2010). The decision to use a purposive sample of experts from three professional positions, from libraries with a minimum staffing level of 10 , while providing the opportunity to gather valuable data, also limited the sample size. There remained a considerable pool of library staff in the VET sector, particularly in the New Zealand ITP sector, who could also have contributed to the study under different criteria.

The study measured participants' perceptions and intentions at a point in time. Given that perceptions and intentions are shaped by experience and change over time, the study provides a snapshot of library staff intention to use mobile technology for service delivery at the time of the research. Unsurprisingly, because the move to mobile service delivery was regarded by participants as imperative, a number of respondents indicated their answers would be very different within the coming year. Further study in this area would contribute to our understanding. The present model has been presented to encourage debate and future research.

\section{Conclusion}

The purpose of this study was to investigate the current state of preparedness of VET sector library staff to implement service delivery to the mobile devices students were bringing on campus. By applying a theoretical lens through which to examine the findings, an abstract theory emerged with the potential to explain in generalised terms the complexities of the phenomenon under investigation. The theory highlights the existing wider environmental factors that brought the problem into focus. It moves through several thematic layers where the individual forms the unit of analysis and concludes at organisational level. Within the interrelationships depicted, a central core relating to impact provides a pivot around which the findings revolve. 
The development of the theoretical model in the present study serves to capture and portray the major factors identified by VET library staff as influencing both personal acceptance and use of mobile technologies, and also library/organisational level factors that influence this use and the development and delivery of mobile library services. It has potential for application beyond the VET sector, and further testing of the model in a variety of contexts could contribute to greater understanding of the impact of mobile technologies within the workplace environment. The study sought to gather information on the VET sector library profession; a small, unique sample limited to a certain geographic area - Australia and New Zealand. While it is possible to postulate the applicability of the findings to libraries in both developed and developing countries, as a contribution to further research, it would be useful to extend the present investigation to other library sectors and regions to enable comparative findings. Such information would strengthen the understanding of the profession's reaction to innovation and technological change.

Several associated areas would benefit from investigation. Moving beyond the intention to deliver mobile library services as a consequence of competency in the use of mobile technologies, the quality of that service delivery is crucial to its acceptance by, and the benefits for, users. The sustained development and delivery of high quality services to mobile devices as a consequence of library staff competence with mobile technologies is an area yet to be investigated. In order to test the relationship between competency with mobile technologies and service quality it is suggested that mobile technologies usage behaviour and service delivery be extended into the area of service quality; that is measurement of the difference between what the user expects from a service and what is actually provided and continuance intention. Such an investigation would contribute to fuller understanding of the extrinsic consequences of technology acceptance. 


\section{References}

Aldrich A (2010) Universities and libraries move to the mobile web. EDUCAUSE Quarterly 33(2). Available at: http://www.educause.edu/ero/article/universities-and-libraries-move-mobile-web (accessed 15 February 2015).

ALIA TAFE Library Advisory Committee (2009) Key issues, trends and future directions for Australian TAFE libraries. Available at: https://www.google.co.nz/url? sa=t\&rct=j\&q=\&esrc=s\&source=web\&cd=1\&ved=0CCwQFjAA \&url=https $\% 3 \mathrm{~A} \% 2 \mathrm{~F} \% 2 \mathrm{Fwww}$.nla.gov.au\%2Finitiatives $\% 2$ Fmeetings $\% 2$ Fpeakbod\%2Fdocumen ts\%2FALIATAFEPeakBodies2009Report.doc\&ei=2u7fVO7hFcP88QXW8IL YDw\&usg=AFQj CNGSMMBPi0omEAqorY7noFCaXNdijg (accessed 15 February 2015).

Arms WY, Calimlim M and Walle L (2009) EScience in practice: Lessons from the Cornell web lab. D-Lib Magazine 15(5/6). Available at: http://www.dlib.org/dlib/may09/arms/05arms.html (accessed 15 February 2015).

Babbie E (2010) The Practice of Social Research (12 ${ }^{\text {th }}$ ed). Belmont, CA: Wadsworth Cengage Learning.

Canuel R and Crichton C (2010) Canadian academic libraries and the mobile web. New Library World 112(3/4): 107-120.

Cao Y, Tin T, McGreal R, Ally M and Coffey S (2006) The Athabasca University mobile library project: Increasing the boundaries of anytime and anywhere learning for students. In: IWCMC'06, July 3-6, 2006, Vancouver, British Columbia, Canada. Available at: https://wiki.library.oregonstate.edu/confluence/download/attachments/3670056/p1289-cao.pdf (accessed 15 February 2015).

Charmaz K (2000) Grounded theory: Objectivist and constructivist methods. In: Denzin NK and Lincoln YS (eds) Handbook of Qualitative Research, $\left(2^{\text {nd }}\right.$ ed). Thousand Oaks, CA: Sage, pp.509-535.

Chenitz WC and Swanson JM (1986) Qualitative research using grounded theory. In: Chenitz WC and Swanson JM (eds) From Practice to Grounded Theory: Qualitative Research in Nursing. Menlo Park, CA: Addison-Wesley, pp.3-15. 
Cohen L, Manion L and Morrison K (2010) Research Methods in Education (6 ${ }^{\text {th }}$ ed). London; New York: Routledge.

Denscombe M (2010) The Good Research Guide for Small-scale Social Research Projects (4 ${ }^{\text {th }}$ ed). Maidenhead: Open University Press.

Emanuel J (2010) The $21^{\text {st }}$ century mobile library: Refining the concept of the anywhere, anytime library within the global context. Available at: https://www.ideals.illinois.edu/bitstream/handle/2142/17344/The\%2021st\%20Century\%20Mobil e\%20Library.pdf?sequence=2 (accessed 15 February 2015).

Evans D (2005) Potential uses of wireless and mobile learning. Landscape study in wireless and mobile learning in the post-16 sector. Available at:

http://www.jisc.ac.uk/uploaded documents/Potential\%20Uses\%20FINAL\%202005.doc (accessed 23 March 2012).

Facer K, Faux F and McFarlane A (2005) Challenges and opportunities: Making mobile learning a reality in schools. Available at: http://www.mlearn.org.za/CD/papers/Facer\%20-\%20Faux\%20\%20McFarlane.pdf (accessed 15 February 2015).

Glaser BG and Strauss AL (1999) The Discovery of Grounded Theory: Strategies for Qualitative Research. New York: Aldine de Gruyter.

Gray D (2004) Doing Research in the Real World. London: Sage.

Hallam G (2008) NeXus: An investigation into the library and information services workforce in Australia. Final report. Canberra: Australian Library and Information Association. Available at: http://eprints.qut.edu.au/12908/1/NeXus_StageOne_sectors_and_states_Final.pdf (accessed 15 February 2015).

Hallam G (2009) NeXus2: An investigation into the library and information services workforce in Australia. The institutional perspective: Final report. Canberra: Australian Library and Information Association. Available at: http://eprints.qut.edu.au/29051/1/29051.pdf (accessed 15 February 2015). 
Hitch L and McCord A (2004) Of nomadicity, expectations, campus IT infrastructure and, oh yes, budget. Available at: http://net.educause.edu/ir/library/pdf/DEC0404.pdf (accessed 15 February 2015).

Jasperson JS, Carter PE and Zmud RW (2005) Comprehensive conceptualization of the post-adoptive behaviors associated with the post-adoptive behaviors associated with IT-enabled work systems. MIS Quarterly 29(3): 525-557.

Kim SH, Mims C and Holmes KP (2006) An introduction to current trends and benefits of mobile wireless technology use in higher education. AACE Journal 14(1): 77-100.

Kroski E (2013) 10 great technology initiatives for your library. American Libraries January/February, 2013. Available at:

http://www.americanlibrariesmagazine.org/issue/januaryfebruary-2013 (accessed 15 February 2015).

Latham B and Poe JW (2012) The library as partner in university data curation: A case study in collaboration. Journal of Web Librarianship 6(4): 288-304.

Lever KM and Katz JE (2007) Cell phones in campus libraries: An analysis of policy responses to an invasive mobile technology. Information Processing and Management 43(4): 1133-1139.

Lippincott JK (2008a) Mobile technologies, mobile users: Implications for academic libraries. ARL: A Bimonthly Report 261. Available at:

http://www.arl.org/storage/documents/publications/arl-br-261.pdf (accessed 15 February 2015).

Lippincott JK (2008b). Libraries and Net Gen learners: Current and future challenges in the mobile society. In Needham G and Ally M (eds) M-libraries: Libraries on the Move to Provide Virtual Access. London: Facet, pp.17-27.

Maesaroh I and Genoni P (2009) Education and continuing professional development for Indonesian academic librarians: A survey. Library Management 30(8/9): 524-538.

Mtshali E and Iyamu T (2013) Adoption of mobile technology to enhance services at academic library. In Blooma J, Nkhoma M and Leung N (eds) Proceedings of the $4^{\text {th }}$ International Conference on Information Systems Management and Evaluation, ICIME 2013, RMIT 
University, Ho Chi Minh City, Vietnam, 13-14 May 2013. Reading, UK: Academic Conferences and Publishing International, pp.160-167.

Newton MP, Miller CC and Bracke MS (2011) Librarian roles in institutional repository data set collecting: Outcomes of a research library task force. Collection Management 36(1): 53-67.

Pang N and Johanson G (2008) Library manager perspectives of the Vocational Education sector: Investigating trends and issues within a learning commons paradigm. Paper presented at VALA2008: libraries/changing spaces, virtual places: conference proceedings, 14th Biennial Conference \& Exhibition, 5-7 February 2008, Melbourne Convention Centre, Australia, pp. 116). Available at: http://www.valaconf.org.au/vala2008/papers2008/81_Pang_Final.pdf (accessed 15 February 2015).

Rabina DL and Walczyk DJ (2007) Information professionals' attitude toward the adoption of innovations in everyday life. Proceedings of the Sixth International Conference on Conceptions of Library and Information Science-"Featuring the Future". Information Research 12(4). Available at: http://informationr.net/ir/12-4/colis/colis12.html (accessed 15 February 2015).

Rogers EM (2003) Diffusion of Innovations $\left(5^{\text {th }}\right.$ ed). New York; London: Free Press.

Saxena A and Yadav RD (2013) Impact of mobile technology on libraries: A descriptive study. International Journal of Digital Library Services 3(4): 1-13.

Sharma D and Sahoo DR (2014) Application of mobile technology in library service: An overview. International Journal of Information Technology and Library Service 3(1): 17-24.

Sharples M, Taylor J and Vavoula G (2005) Towards a theory of mobile learning. Available at: http://www.mlearn.org/mlearn2005/CD/papers/Sharples-\%20Theory\%20of\%20Mobile.pdf (accessed 15 February 2015).

Silverman D (2010) Doing Qualitative Research: A Practical Handbook (3 ${ }^{\text {rd }}$ ed). London: Sage.

Traxler J (2008) Use of mobile technology for mobile learning and mobile libraries in a mobile society. In Needham G and Ally M (eds) M-libraries: Libraries on the Move to Provide Virtual Access. London: Facet, pp.47-55. 
Valk J-H, Rashid AT and Elder L (2010) Using mobile phones to improve educational outcomes: An analysis of evidence from Asia. The International Review of Research in Open and Distance Learning 11(1). Available at: http://www.irrodl.org/index.php/irrodl/rt/printerFriendly/794/1487 (accessed 15 February 2015).

Venkatesh V, Brown SA, Maruping LM and Bala H (2008) Predicting different conceptualizations of system use: The competing roles of behavioural intention, facilitating conditions and behavioural expectation. MIS Quarterly 32(3): 483-502.

Weir A (2000) The information professional of the future: What skills will be needed and how will they be acquired? Available at: http://pandora.nla.gov.au/pan/13910/200201070000/www.alia.org.au/conferences/alia2000/proceedings/aileen.weir.html (accessed 15 February 2015).

Yi MY, Jackson JD, Park JS and Probst JC (2006) Understanding information technology acceptance by individual professionals: Toward an integrative view. Information \& Management 43(3): 350363.

Younas M and Mostéfaoui SK (2011) A new model for context-aware transactions in mobile services. Personal and Ubiquitous Computing 15(8): 821-831. 